\title{
Pengaruh Intensitas Curah Hujan dan Kemiringan Lereng Terhadap Erosi yang Berpotensi Longsor
}

\author{
Farid Sitepu*1, Mary Selintung $^{1}$, Tri Harianto ${ }^{1}$ \\ ${ }^{1}$ Jurusan Teknik Sipil, Fakultas Teknik, Universitas Hasanuddin \\ Jalan Poros Malino, KM.6, Bontomarannu 92172, Gowa, Sulawesi Selatan \\ *Email: farid.sitepu@unhas.ac.id
}

DOI: 10.25042/jpe.052017.03

\begin{abstract}
Abstrak
Wilayah Indonesia yang berada pada belahan dunia yang memiliki iklim hujan tropis menyebabkan bervariasinya intensitas curah hujan. Intensitas curah hujan akan sangat berpengaruh pada kestabilan tanah sebagai dasar pondasi sebuah struktur sipil. Dalam penelitian ini ditinjau pengaruh intensitas curah hujan dan kemiringan lereng dalam upaya pencegahan kerusakan struktur maupun kejadian bencana yang dapat ditimbulkan. Dilakukan pengujian laboratorium dengan menggunakan metode pembanding Universal Soil Loss Equation untuk menentukan besarnya erosi yang terjadi pada lereng tanah dengan kadar organik 18,67\% dengan tingkat kepadatan 60\% dan 70\%. Dengan menggunakan Rainfall Simulator digunakan variasi intensitas hujan $23 \mathrm{~mm} / \mathrm{jam}, 34 \mathrm{~mm} / \mathrm{jam}$ dan $51 \mathrm{~mm} / \mathrm{jam}$ diperoleh peningkatan nilai erosi tanah sebesar $40 \%$ dari intensitas tertinggi ke intensitas terendah. Dari faktor kemiringan lereng dimodelkan kemiringan $10^{\circ}, 15^{\circ}$ dan $20^{\circ}$ dan didapatkan hasil peningkatan nilai erosi sebesar $3 \%$.
\end{abstract}

\begin{abstract}
The Effect of Rainfally and Land Slope to Erosion which Could Cause A Landslide. Indonesian region is located on tropical rain forest territory on earth causes variations of high intensity of rainfall. The intensity of rainfall will greatly affect the stability of soils as a foundation ground of a civil structure. In this study reviewed the influence of rainfall intensity and slope in the prevention of structural damage or catastrophic events that may occur. Experimental research conduct using comparison method Universal Soil Loss equation to determine the amount of erosion on the slope of ground with organic content of 18.67 with a density of $60 \%$ and $70 \%$. Rainfall simulator used to set variations of rainfall intensity by $23 \mathrm{~mm} /$ hour, $34 \mathrm{~mm} /$ hour and $51 \mathrm{~mm} /$ hour is obtained an increase in ground erosion by $40 \%$ from the highest intensity to the lowest intensity. From the slope factor, sample is modeled slope with $10^{\circ}, 15^{\circ}$ and $20^{\circ}$ and showed increase of erosion up to $3 \%$.
\end{abstract}

Kata-kunci: Erosi lereng, intensitas hujan, tanah organik

\section{Pendahuluan}

Beberapa faktor yang mempengaruhi erosi pada tanah antara lain kemiringan lereng, intensitas curah hujan, jenis tanah, vegetasi, kecepatan permeabilitas dan juga faktor manusia. Hujan yang jatuh ke permukaan tanah memiliki energi kinetik yang besar dan berpotensi menghancurkan partikel-partikel tanah dan akan membuat kondisi tanah menjadi tidak stabil. Besarnya curah hujan menentukan kekuatan dispersi, daya pengangkutan dan kerusakan pada tanah [1].

Erosi tanah oleh air terjadi jika kondisi tanah jenuh sehingga sulit untuk terinfiltrasi. Air kemudian mengalir di permukaan dan mengangkut butiran-butiran tanah. Erosi tanah adalah bergeraknya butiran tanah oleh angin atau air [2].

Erosi menyebabkan hilangnya lapisan atas tanah yang subur untuk pertumbuhan tanaman serta berkurangnya kemampuan tanah untuk menyerap dan menahan air sehingga permeabilitas tanah menjadi tinggi dan menyebabkan kadar air dalam tanah bertambah. Dengan kadar air yang sangat besar yang terkandung dalam tanah akan menyebabkan kuat geser tanah menjadi lemah dan berpotensi terjadi longsoran. Beberapa peneliti menyatakan bahwa intensitas hujan yang tinggi memiliki hubungan langsung dengan keruntuhan lereng [3]. 


\section{Metodologi}

\subsection{Kepadatan dan Kemiringan Lereng}

Tanah yang digunakan merupakan jenis tanah organik dengan kadar 18,67\%. Sampel tanah untuk model uji dibuat dalam dua kondisi yaitu kepadatan tanah $60 \%$ dan $70 \%$. Metode USLE menggunakan variable I (intensitas), Ek (energi kinetik), $\mathrm{R}$ (erosivitas hujan), $\mathrm{K}$ (erodibilitas tanah), S (Kemiringan), LS (Panjang Lereng), $\mathrm{C}$ (faktor vegetasi) dan $\mathrm{P}$ (faktor pelaksanaan pengendali erosi) untuk memperhitungkan erosi tanah. Pada penelitian ini hanya menggunakan variable intensitas (I), kemiringan (S) dan kepadatan tanah (D). Penentuan kemiringan lereng berdasarkan USLE kondisi tanah curam 9$25^{\circ}$. Dalam penelitian ini digunakan kemiringan $10^{\circ}, 15^{0}$ dan $20^{\circ}$ sebagai variasi untuk mengetahui laju erosi terhadap kemiringan curam.

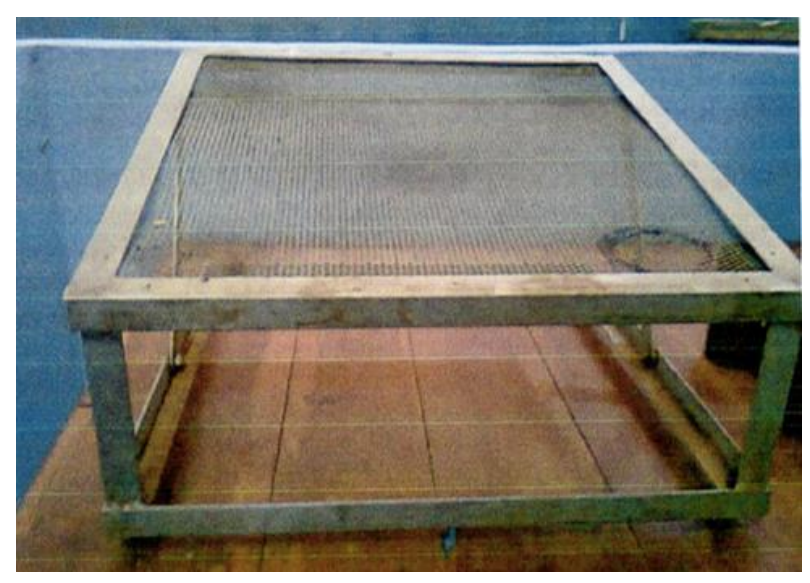

Gambar 1. Alat Pengatur Kemiringan Lereng

\subsection{Intensitas Hujan Buatan}

Standar kondisi hujan lebat $10-20 \mathrm{~mm} / \mathrm{jam}$, dan kondisi hujan sangat lebat yaitu $>20 \mathrm{~mm} / \mathrm{jam}$. Dengan menggunakan alat rainfall simulator intensitas hujan di set sesuai desain yang dipergunakan dalam penelitian yaitu intensitas 23 $\mathrm{mm} / \mathrm{jam}, 34 \mathrm{~mm} / \mathrm{jam}$ dan $51 \mathrm{~mm} / \mathrm{jam}$. Intensitas hujan dihitung dengan rumus :

$$
I=\frac{Q}{A \times t} \times 600
$$

\section{Dimana :}

$\mathrm{Q}=$ volume air dalam setiap kontainer $(\mathrm{ml})$

$\mathrm{A}=$ Luas kontainer $\left(\mathrm{cm}^{2}\right)$

$\mathrm{T}=$ waktu (menit)

$\mathrm{I}=$ intensitas $(\mathrm{mm} / \mathrm{jam})$
2.3. Energi Kinetik Hujan dan Besaran Erosi

Nilai intensitas hujan yang didapatkan selanjutnya dimasukkan kedalam rumus energi kinetik menurut Wischmeier dan Hudson [4, 5]:

$$
E k=13.32+9.78 \log I
$$

Dimana :

I = Intensitas hujan $(\mathrm{mm} / \mathrm{jam})$

$\mathrm{Ek}=$ Energi kinetik (joule)

Untuk daerah tropis, Hudson menganjurkan untuk menggunakan rumus [4]:

$$
E k=29.8-\frac{127.5}{I}
$$

Kemampuan hujan untuk menimbulkan erosi disebut Indeks daya erosi curah hujan (R) dapat ditulis dalam bentuk :

$$
R=\frac{E k I_{30}}{100}
$$

Dimana :

$\mathrm{Ek}=$ Energi kinetik hujan (joule)

$\mathrm{I}_{30}=$ intensitas hujan 30 menit maksimum

\section{Hasil dan Pembahasan}

\subsection{Hasil Uji dan Perhitungan}

Tanah sampel uji yang digunakan terlebih dahulu diuji kadar organiknya untuk mengetahui besarnya kandungan organik dalam tanah. Dari berat isi kering yang didapatkan dari pengujian digunakan untuk mendapatkan kepadatan sesuai dengan desain $60 \%$ dengan berat isi kering 1,23 $\mathrm{gr} / \mathrm{cm}^{3}$ dan $70 \%$ dengan berat isi $1.25 \mathrm{gr} / \mathrm{cm}^{3}$.

Hasil uji karakteristik tanah yang digunakan dalam penelitian ini adalah sebagai berikut :

Tabel 1. Hasil Pemeriksaan Tanah

\begin{tabular}{ll}
\hline \multicolumn{1}{c}{ Uraian } & Nilai \\
\hline Fraksi butiran Kasar & $65.15 \%$ \\
Fraksi Butiran Halus & $34.85 \%$ \\
Indeks Plastisitas & $10.38 \%$ \\
Berat Isi Kering & $1.23 \mathrm{gr} / \mathrm{cm} 3$ \\
Kadar air potimum & $28.27 \%$ \\
Kadar Unorganik & $81.33 \%$ \\
Kadar Organik & $18.67 \%$ \\
\hline
\end{tabular}

Intensitas hujan buatan yang dipergunakan hasil dari uji dengan menggunakan Rainfall Simulator adalah sebesar $23 \mathrm{~mm} / \mathrm{jam}, 34 \mathrm{~mm} / \mathrm{jam}$ dan $51 \mathrm{~mm} / \mathrm{jam}$ yang selanjutnya dihitung 
besarnya energi kinetik (Ek) yang dihasilkan dari intensitas hujan tersebut dengan menggunakan persamaan Wischmeier dan Hudson. Hasil perhitungan dapat dilihat pada table dibawah :

Tabel 2. Energi Kinetik hujan buatan

\begin{tabular}{ccc}
\hline Intensitas & $\begin{array}{c}(\mathrm{A}) \\
\text { Energi kinetik } \\
\text { (joule) }\end{array}$ & $\begin{array}{c}(\mathrm{B}) \\
\text { Energi kinetik } \\
\text { (joule) }\end{array}$ \\
\hline 23 & 24.174 & 26.57 \\
34 & 26.065 & 28.56 \\
51 & 27.303 & 30.03 \\
\hline
\end{tabular}

Ket. (A) Wischmeier dan (B) Hudson

Perhitungan besarnya erosi diketahui melalui rangkaian pengujian di laboratorium dengan bantuan alat Rainfall Simulator dan dihitung dengan metode USLE (Universal Soil Loss Equation) pada tanah.

\subsection{Pengaruh Intensitas Hujan Terhadap Jumlah Laju Erosi}

Data pengukuran jumlah laju erosi didapatkan dari perhitungan prosentasi jumlah tanah yang ter-erosi hasil pengujian intensitas hujan dengan kemiringan lereng tertentu. Secara umum meningkatnya intensitas akan meningkatkan jumlah laju erosi. Semakin banyak butiran air yang menyentuh permukaan tanah. Semakin banyaknya butiran air yang jatuh ke permukaan tentu saja dengan energi kinetik yang semakin banyak terjadi di permukaan tanah yang semakin memperbesar potensi hancurnya agregat tanah.

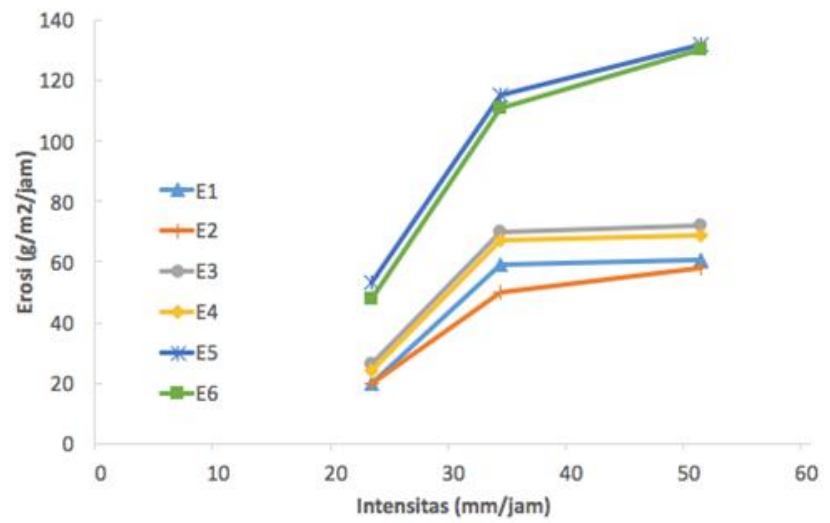

Gambar 2. Grafik Pengaruh Intensitas Terhadap Erosi hasil penelitian

Hasil pengujian menunjukkan terjadinya peningkatan besarnya erosi yang terjadi berbanding lurus dengan peningkatan intensitas hujan. Pada kemiringan lereng $20^{\circ}$ pada tingkat kepadatan $70 \%$ besarnya erosi adalah 48.456 gram, 111.168 gram dan 131,76 gram atau mengalami peningkatan 62.712 gram pada intensitas $\mathrm{I}_{12} \mathrm{ke} \mathrm{I}_{34}$ dan 20.592 pada intensitas $\mathrm{I}_{34}$ ke I51.

Bila dibandingkan dengan metode USLE maka dapat terlihat perbedaan. Perhitungan USLE cenderung menghasilkan data erosi yang berulang.

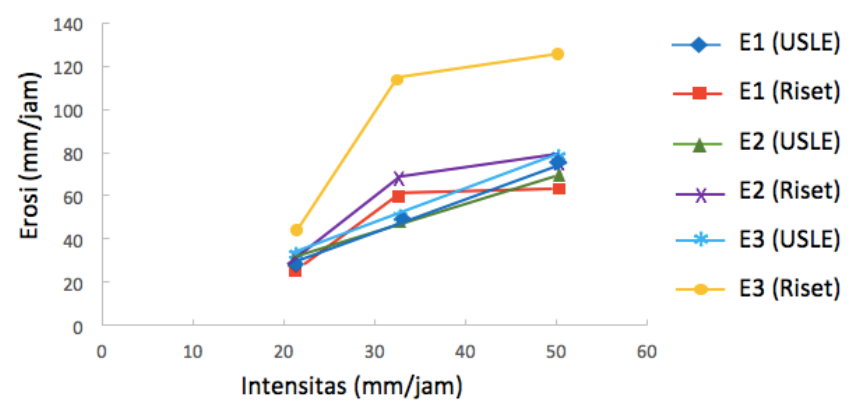

Gambar 3. Grafik Perbandingan Jumlah Erosi Hasil Penelitian dengan Metode USLE Akibat Pengaruh Intensitas

Jumlah laju erosi menurut USLE menghasilkan nilai yang lebih kecil jika dibandingkan dengan penelitian, akan tetapi memiliki persamaan yaitu meningkatnya intensitas akan meningkatkan laju erosi. Terjadinya perbedaan hasil yang didapatkan disebabkan oleh beberapa hal berikut :

1. Faktor utama yang paling mempengaruhi laju erosi pada penelitian adalah intensitas hujan, sehingga perubahan intensitas akan mempengaruhi secara langsung terhadap perubahan laju erosi. Sedangkan pada metode USLE terdapat beberapa faktor utama yang mempengaruhi laju erosi, sehingga perubahan intensitas tidak menimbulkan perubahan laju erosi secara signifikan tanpa disertai adanya perubahan dari faktor-faktor lainnya.

2. Metode USLE tidak memperhitungkan faktor kepadatan tanah dalam pendugaan jumlah laju erosi, sehingga jumlah laju erosi yang dihasilkan pada variasi satu kemiringan adalah sama untuk setiap variasi kepadatan.

3. Adanya perbedaan kondisi model fisis dengan kondisi actual dilapangan, terutama dengan metode simulasi hujan. Dengan intensitas yang sama belum bias ditirukan secara tepat dari segi distribusi hujan dan kecepatan jatuh butiran.

\subsection{Pengaruh Kemiringan Lereng Terhadap} Jumlah Laju Erosi

Hasil dari pengujian atas pengaruh kemiringan lereng sebesar $10^{0}, 15^{\circ}$ dan $20^{\circ}$ terhadap erosi ditunjukkan pada gambar dibawah ini : 


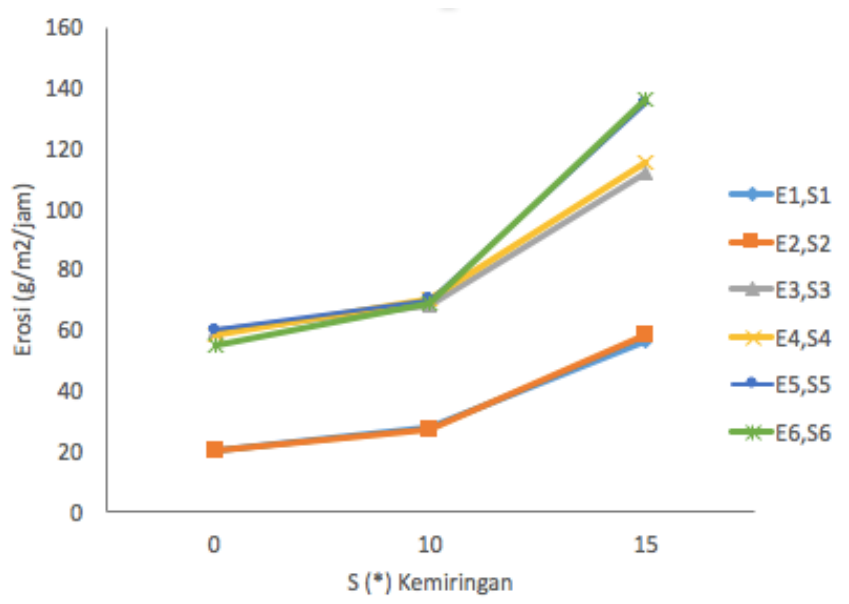

\section{Gambar 4. Grafik Pengaruh Kemiringan Terhadap} Erosi

Untuk kepadatan $60 \%$ dan intensitas 23 $\mathrm{mm} / \mathrm{jam}$ dengan kemiringan 100, 150 dan 200 berturut-turut jumlah erosi yaitu 23,04 gram, 29,616 gram dan 51,96 gram. Hal ini menunjukkan terjadinya peningkatan jumlah erosi sebesar 6.58 gram dan 22.34 gram. Hal yang sama terjadi pada kepadatan $70 \%$ dimana semakin besar kemiringan lereng maka semakin besar pula laju erosi yang dihasilkan. Kemiringan lereng yang lebih besar menyebabkan partikel tanah mudah lepas.

\subsection{Pengaruh Kepadatan terhadap Jumlah Laju Erosi}

Grafik dibawah menunjukkan hubungan kepadatan dengan jumlah laju erosi. Dua kondisi kepadatan tanah yang diuji adalah $60 \%$ dan $70 \%$.

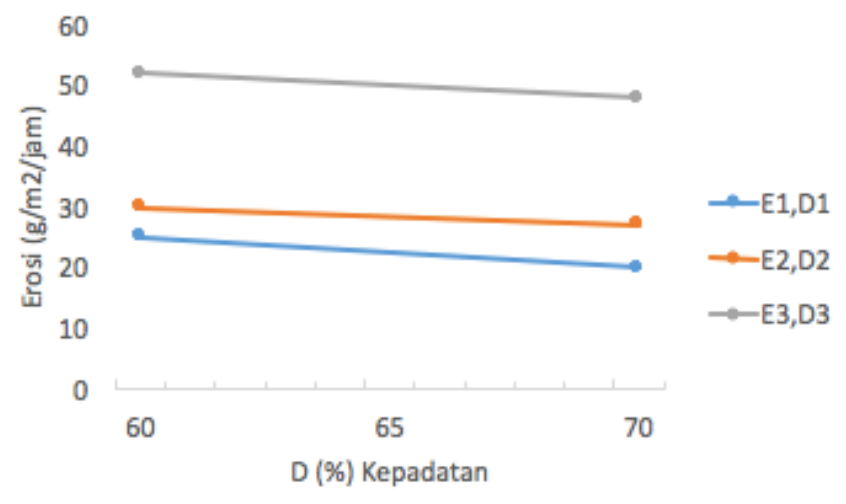

Gambar 5. Grafik Pengaruh Kepadatan Terhadap Besarnya Laju Erosi

Jumlah erosi pada kemiringan lereng $20^{\circ}$ dengan kepadatan tanah dan intensitas hujan yang sama adalah 51,96 gram dan 48,46 gram atau terjadi penurunan sebesar 3,5 gram.

\subsection{Prediksi Jumlah Laju Erosi}

Pendugaan jumlah laju erosi dilakukan untuk memperkirakan besarnya laju erosi yang terjadi berdasarkan pengujian-pengujian yang telah dilakukan. Untuk memprediksi hasil erosi yang terjadi, maka diperlukan untuk mencari persamaan-persamaan dari data deskrit yang ada. Persamaan-persamaan tersebut diperoleh dengan melakukan analisa regresi terhadap variablevariabel yang berhubungan. Pendugaan terhadap besarnya laju erosi dalam penelitian ini menggunakan analisa regresi power yang paling mewakili sebaran data yang ada.

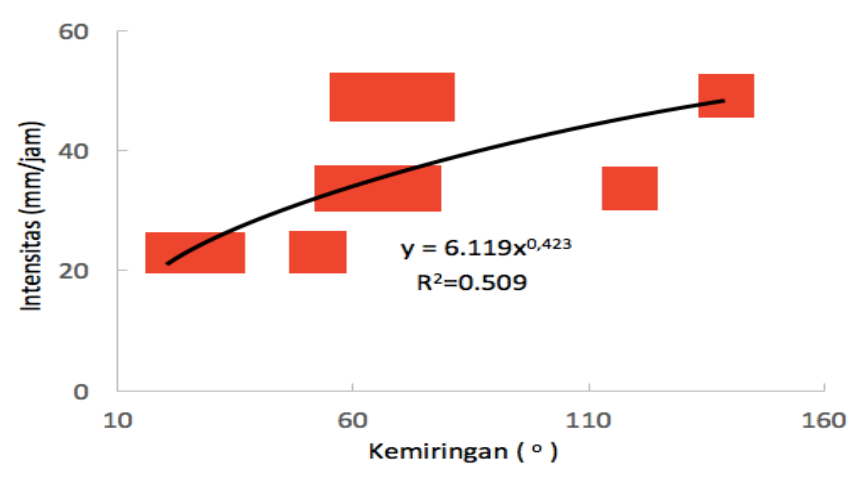

Gambar 6. Grafik Regresi Jumlah Erosi Pada Kemiringan $10^{0}, 1^{0}$, dan $20^{\circ}$.

Nilai R yang dihasilkan oleh analisa regresi power merupakan nilai yang terbesar disbanding dengan analisa regresi lainnya, bahkan ada yang mencapai 1 . Salah satu penyebab nilai $\mathrm{R}=1$ adalah data yang dianalisa pada regresi hanya 3 . Analisa regresi ini mendukung hasil penelitian, bahwa faktor intensitas merupakan faktor yang sangat mempengaruhi jumlah laju erosi, dimana faktor intensitas ini sangat mempengaruhi besarnya energi kinetik.

Dari Gambar 6 didapatkan persamaan yaitu :

$$
F(x)=6.119 x^{0,423}
$$

Dengan menggunakan persamaan ini jumlah laju erosi pada jenis tanah organik dengan variasi intensitas curah hujan, variasi kemiringan dan kepadatan bisa diketahui.

\subsection{Pengukuran Jumlah Laju Erosi dengan Metode USLE}

Jumlah laju erosi (E) untuk kondisi penelitian dan metode USLE menggunakan satuan $\mathrm{gr} / \mathrm{m}^{2} / \mathrm{jam}$. Faktor erosivitas hujan (R) pada persamaan USLE disesuaikan dengan nilai masing-masing intensitas yang berarti nilai yang digunakan metode USLE sama dengan besarnya variasi dari masing-masing intensitas. Faktor erodibilitas tanah $(\mathrm{K})$ berdasarkan hasil pengujian properties tanah digolongkan kedalam jenis 
granuler sedang sampai kasar dengan nilai $\mathrm{K}$ sebesar 0.64. Faktor panjang lereng (LS) dimana $\mathrm{L}$ yang digunakan adalah 0.5 atau sama dengan panjang sampel, sedangkan nilai S digunakan $10^{\circ}$, $15^{0}$ dan $20^{0}$ sesuai dengan kemiringan yang didesain dalam penelitian ini.

Faktor pengelolaan vegetasi (C) yang digunakan adalah lahan tanpa vegetasi sehingga nilai $\mathrm{C}=1$. Dan faktor pelaksanaan pengendalian erosi (P) diasumsikan sebagai tanah tanpa tindakan pengendalian erosi, sehingga $\mathrm{P}$ yang digunakan adalah 1. Hal ini sama dengan tanah yang tererosi karena intensitas hujan, kemiringan dan kepadatan tanpa ada usaha mengurangi erosi.

\section{Kesimpulan}

Dari hasil pengujian sampel dan analisa yang dilakukan dalam penelitian ini dapat ditarik beberapa kesimpulan antara lain :

1. Kandungan bahan organik pada tanah dapat mengurangi terjadinya erosi karena bahan organik mengandung unsur hara yang menyebabkan tumbuhan tumbuh subur sehingga energi kinetik yang terjadi akibat butiran air yang menyentuh permukaan bias dikurangi.

2. Intensitas curah hujan memiliki pengaruh yang berbanding lurus dengan erosi. Intensitas hujan yang tinggi akan menambah besarnya laju erosi tanah yaitu $\mathrm{I}_{23}, \mathrm{I}_{34}$ dan $\mathrm{I}_{51}$ masing-masing sebesar 23,04 g/m²/jam, 59,52 $\mathrm{g} / \mathrm{m}^{2} / \mathrm{jam}$ dan $61,68 \mathrm{~g} / \mathrm{m}^{2} / \mathrm{jam}$.
3. Kemiringan lereng menghasilkan pengaruh yang berbanding lurus dengan erosi tanah. Dimana penelitian ini menunjukkan pada kemiringan 100, 150 dan 200 diperoleh jumlah erosi masing-masing 23,04 g/ $\mathrm{m}^{2} / \mathrm{jam}, 29,616$ $\mathrm{g} / \mathrm{m}^{2} / \mathrm{jam}$ dan $51,96 \mathrm{~g} / \mathrm{m}^{2} / \mathrm{jam}$.

4. Kepadatan tanah menghasilkan pengaruh yang berbanding terbalik dengan jumlah erosi. Dimana erosi mengalami penurunan saat kepadatan $60 \%$ terjadi sebesar $23,04 \mathrm{~g} / \mathrm{m}^{2} / \mathrm{jam}$ dan kepadatan $70 \%$ diperoleh erosi sebesar $20,4 \mathrm{~g} / \mathrm{m}^{2} / \mathrm{jam}$.

\section{Daftar Pustaka}

[1] Arsyad, "Evaluasi Kemampuan Lahan dan Tingkat Bahaya Erosi Untuk Prioritas Konservasi Lahan di Daerah Aliran Sungai Takapala Kabupaten Dati II Gowa Propinsi Sulawesi Selatan". Tesis. 1989. Program Pascasarjana UGM. Yogyakarta.

[2] Kirby. M. J. \& Morgan. R.P. “Soil Erosion”. John Willey \& Sons Ltd. 1980. USA.

[3] Chen. H., Lee C. and Law K. "Causative Mechanisms of Rainfall-Induced Fill Slope Failures". Journal of Geotechnical and Geo-environmental Engineering. 2004. Vol.130. Issue June 2004, P.593-602.

[4] Hudson. N. "Field measurement of Soil Erosion and Runoff, Issue 68. Food and Agriculture Organization of The United Nations. 1993. Pp.121-126. ISBN 9789251034064.

[5] Wischmeier. W.H., Johnson. C.B. and Cross. B.V. "A soil erodibility nomograph for farmland and construction sites". Journal of Soil and Water Conservation. 1971. 26:189-193. ISSN 1941-3300. 